\title{
Powders of metal borides obtained by the SHS method and low-temperature plasma
}

\author{
Ilya Zhukov ${ }^{1,2}$, Alexander Vorozhtsov ${ }^{1,2}$, Vladimir Promakhov ${ }^{1,2}$, Yana Dubkova ${ }^{2,}$, Alexander Zhukov ${ }^{2}$, \\ and Anton Khrustalev ${ }^{2}$ \\ ${ }^{1}$ Institute for Problems of Chemical \& Energetic Technologies of the SB RAS, 1, Sotsialisticheskaja str., Biysk, 659332, Russia \\ ${ }^{2}$ National Research Tomsk State University, 36 Lenin Ave., Tomsk, 634050, Russia
}

\begin{abstract}
This paper introduces principle possibility of producing aluminum and titanium boride predetermined morphology using the SHS method and plasma processing. Thermal analysis data for synthesized boride powders in comparison with boron powder and nano-sized aluminum are presented It was found that the synthesized metal borides, according to the thermal analysis data, are promising as a fuel in high-energy materials: the oxidation state of $\mathrm{AlB}_{2}$ is $\sim 80 \%$, at a degree of boron oxidation $\sim 20 \%$, aluminum $\sim 67 \%$.
\end{abstract}

\section{Introduction}

With the modern development of the aviation and aerospace industries, there is an increasing need for the development of new materials to improve the performance characteristics of aircraft. In addition to the improvement of materials for the spacecraft skin, its structural parts and electronics, the development of new types of energy materials that can improve fuel efficiency is of great importance. Increasing the heat of combustion, burning rate, density and other thermodynamic and mechanical characteristics of fuels is a top priority for the transport and aerospace industry. Aluminum is an accepted and relatively inexpensive metal. However, with the widespread use of aluminum in fuels, certain disadvantages were found. The main obstacle to the expansion practical use of aluminum is due to the incompleteness of its combustion. One of the optimal solutions to the problem of increasing the efficiency of metal additives in fuels today is a complete or partial transition to the use of boron or metal borides $[1,2]$. Heat of combustion, for boron is almost two times higher than for aluminum [3, 4]. Owing to this characteristic, it is possible to significantly reduce the specific propellant consumption, increase the density of impulse, as well as achieve higher aircraft speeds.

The oxidation of boron particles unfortunately results in the formation of a solid layer of oxide $\mathrm{B}_{2} \mathrm{O}_{3}$ and the diffusion of oxygen through this layer is hindered. The oxidation of metal borides does not result in the formation of an oxide layer impenetrable for oxygen [5]. Diffusion of oxygen through the faulted layer of complex oxides is facilitated and the degree and rate of oxidation is increased. The use of potentially high boron exothermicity becomes possible if it is used in the form of metal borides which also have high values of the heat of combustion. It was found that aluminum and magnesium borides as well as titanium and zirconium are the most promising [6]. Values of the heat of combustion for these borides are given below. Heat of combustion of borides (Table 1) is significantly higher than the values for corresponding metals (Table 2).

Table 1. Heat of combustion of borides [7, 8].

\begin{tabular}{|c|c|}
\hline Borides & $\begin{array}{c}\text { Heat of } \\
\text { combustion, } \mathbf{K J} / \mathbf{g}\end{array}$ \\
\hline $\mathrm{AlB}_{2}$ & 39.5 \\
\hline $\mathrm{AlB}_{12}$ & 50.9 \\
\hline $\mathrm{MgB}_{2}$ & 37.8 \\
\hline $\mathrm{TiB}_{2}$ & 23.9 \\
\hline $\mathrm{Mg}_{0,5} \mathrm{Al}_{0,5} \mathrm{~B}_{2}$ & 38.6 \\
\hline $\mathrm{ZrB}_{2}$ & 17.7 \\
\hline
\end{tabular}

Table 2. Heat of combustion of metals $[9,10]$.

\begin{tabular}{|c|c|}
\hline Element & $\begin{array}{c}\text { Heat of combustion, } \\
\mathbf{K J} / \mathbf{g}\end{array}$ \\
\hline $\mathrm{B}$ & 57.2 \\
\hline $\mathrm{Mg}$ & 25.1 \\
\hline $\mathrm{Al}$ & 31.4 \\
\hline $\mathrm{Ti}$ & 15.7 \\
\hline $\mathrm{Zr}$ & 12.0 \\
\hline
\end{tabular}

*Corresponding author: y.a.dubkova@niipmm.tsu.ru 
The widespread method of obtaining borides is synthesis in an oven furnace; however, this method involves the use of a bulky oven furnace and high energy consumption. Meanwhile, reactions of $\mathrm{Ti}$ and $\mathrm{Al}$ interaction with boron are exothermic, which provides the basis for the process of self-propagating hightemperature synthesis (SHS) of borides [11]. Such synthesis by combustion eliminates the need for application of complicated oven furnace equipment, disadvantage of this method include variation in the dispersion obtained powders and nonspherical particle morphology. This disadvantage arises from the crushing of the produced SHS-sinters by mechanical influences. To optimize the morphology and dispersion of powder materials, powder processing can be applied by lowtemperature plasma [12]. Thus, this work is devoted to the synthesis and investigation of powders of spherical morphology: $\mathrm{TiB}_{2}, \mathrm{AlB}_{2}, \mathrm{AlB}_{12}$.

\section{Experimental part}

The general scheme of the process of production of powders represented in Figure 1.

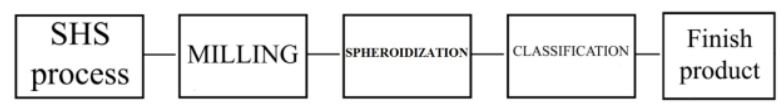

Fig. 1. Technological scheme of obtaining powders of metal borides.

To synthesize borides by combustion, we here used the stoichiometric exothermic charge of aluminum (100 $\mu \mathrm{m})$ and titanium $(40 \mu \mathrm{m})$ powders and amorphous boron $(0.8 \mu \mathrm{m})$ with given reactions:

$$
\begin{gathered}
\mathrm{Ti}+2 \mathrm{~B} \rightarrow \mathrm{TiB}_{2} \\
\mathrm{Al}+2 \mathrm{~B} \rightarrow \mathrm{AlB}_{2} \\
\mathrm{Al}+12 \mathrm{~B} \rightarrow \mathrm{AlB}_{12} .
\end{gathered}
$$

The content of the basic elements in the initial powders exceeded $99 \%$. Synthesis of borides in the SHS conditions was carried out in a laboratory reactor with a volume of 2 liters (Figure 2).

To synthesize aluminum borides, a thermally conjugated SHS process was used because of insufficient exothermicity of the initial charge. The insufficient thermal emission in the process of formation of $\mathrm{AlB}_{2}$ and $\mathrm{AlB}_{12}$ was compensated by the energy of the chemical oven furnace for which $\mathrm{Ti}+\alpha \cdot \mathrm{B}$ mixture was used.

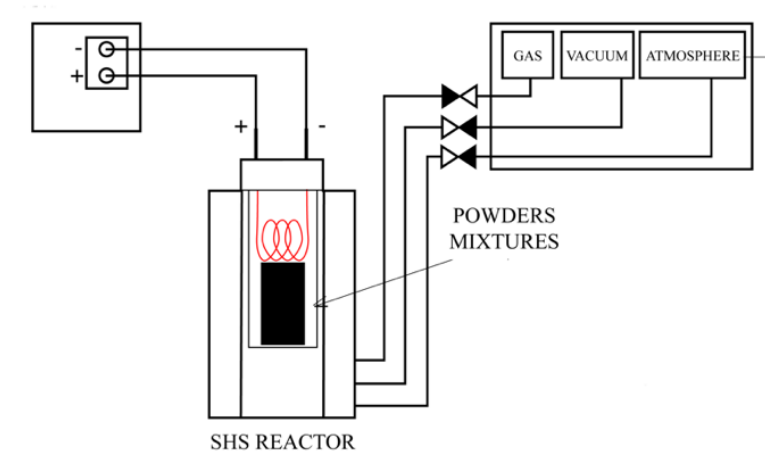

a

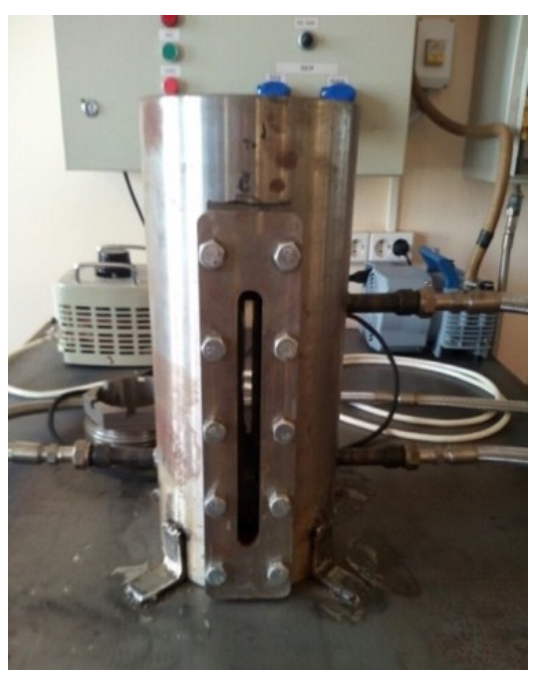

b

Fig. 2. Scheme of a laboratory facility for conducting SHS process (a) and general view (b).

Powders were produced by plasma processing in a high-frequency plasmatron by blowing the powders radially into an argon plasma (Figure 3 ). In a reactor jet 2 through a nozzle 1 a sprayed solution of a given composition is fed into the plasma jet of the coolant created by the plasmatron 3 and a high-frequency generator 4 , the powders are deposited in a collector 5 . Spheroidization was carried out considering the studies of the process of plasma-chemical synthesis aimed at revealing the parameters for obtaining powder particles assigned to the size and morphology [13].

$\mathrm{X}$-ray phase studies were performed on a Schimadzu XRD6000 diffractometer. The morphology of the powders was investigated using a scanning electron microscope Philips SEM 515. To evaluate the possibility of using synthesized borides as components of highenergy materials, a differential thermal analysis was performed using a Netzch STA 409 PC/PG device. 


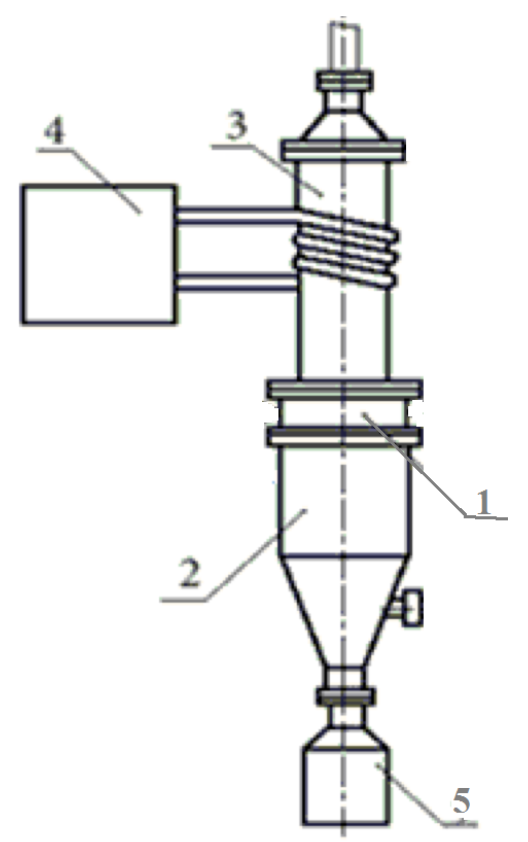

a

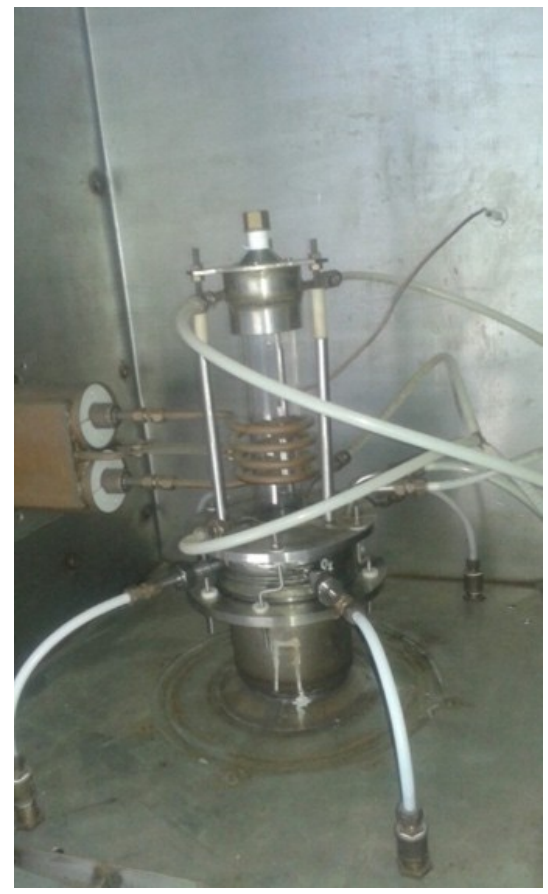

b

Fig. 3. Schematic view (a) and general view (b) of a plasma generator used for plasma processing of powder materials.

\section{Results and discussion}

Figure 4 shows SEM images of the $\mathrm{TiB}_{2}$ powders obtained by the SHS method before and after plasma treatment.
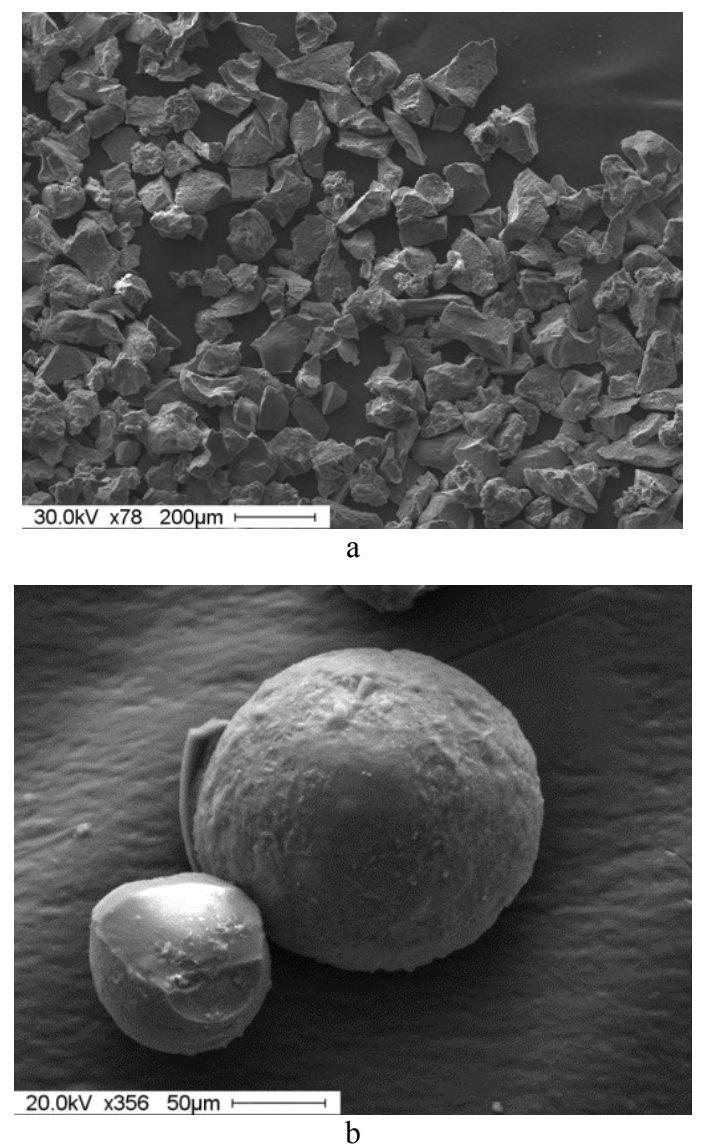

Fig. 4. General view of $\mathrm{TiB}_{2}$ powder before (a) and after (b) plasma treatment.

In the experiment on obtaining $\mathrm{TiB}_{2}$, the maximum burning rate for the stoichiometric $\mathrm{Ti}+2 \mathrm{~B}$ mixture was $\sim 9 \mathrm{sm} / \mathrm{s}$. The measured combustion temperature in this case exceeded $2500{ }^{\circ} \mathrm{C}$ with a calculated $\mathrm{T}_{a d}=3190 \mathrm{~K}$. Combustion synthesis in a highly exothermic $\mathrm{Ti}-\mathrm{B}$ system is realized in a wide range of variation in the ratio of the components of the charge. The limits of combustion in this case depend weakly on the dispersion of the titanium powder. When using a titanium powder with a particle size of less than $40 \mu \mathrm{m}$, the $\mathrm{Ti}+\alpha \cdot \mathrm{B}$ mixture burns at $0.45 \leq \alpha \leq 5.5$ [14].

The X-ray phase analysis demonstrated a large yield of sought-after borides obtained by self-propagating high-temperature synthesis: $88.04 \%$ for $\mathrm{AlB}_{12}, 93.18 \%$ for $\mathrm{AlB}_{2}$, and $98.43 \%$ for $\mathrm{TiB}_{2}$. Figure 5 shows the typical X-ray diffraction pattern of synthesized aluminum diboride. 


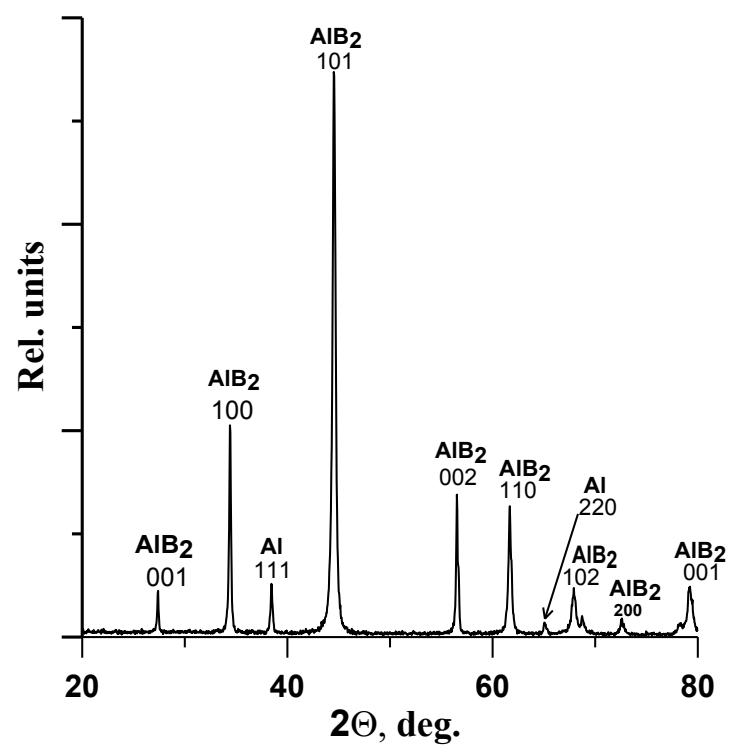

Fig. 5. Typical X-ray diffraction pattern of aluminum diboride obtained by the SHS [15].

Thermal analysis data for synthesized boride powders in comparison with boron powder and nano-sized aluminum are presented in Table 3 and in Figure 6.

The calculation is made by the oxidation reaction equations. For example, for AlB2 with a calculated increase in mass by reaction $\sim 2.26$ times:

$$
2 \mathrm{AlB}_{2}+4.5 \mathrm{O}_{2}=\mathrm{Al}_{2} \mathrm{O}_{3}+2 \mathrm{~B}_{2} \mathrm{O}_{3}
$$

The degree of oxidation is $\sim 80 \%$.

Table 3. Thermal analysis data.

\begin{tabular}{|c|c|c|c|c|c|}
\hline Parameter & Al nano & B & $\mathrm{TiB}_{2}$ & $\mathbf{A l B}_{2}$ & $\mathrm{AlB}_{12}$ \\
\hline $\begin{array}{c}\text { Degree of } \\
\text { oxidation, } \alpha \text {, } \\
\%\end{array}$ & 67 & 20 & 68 & 80 & 58 \\
\hline $\begin{array}{c}\text { Maximum } \\
\text { oxidation } \\
\text { temperature, } \\
T_{\text {Vox }},{ }^{\circ} \mathrm{C}\end{array}$ & 600 & $\begin{array}{c}900 \\
- \\
1000\end{array}$ & $\begin{array}{c}800 \\
- \\
1000\end{array}$ & $\begin{array}{c}1000 \\
- \\
1100\end{array}$ & 800 \\
\hline
\end{tabular}

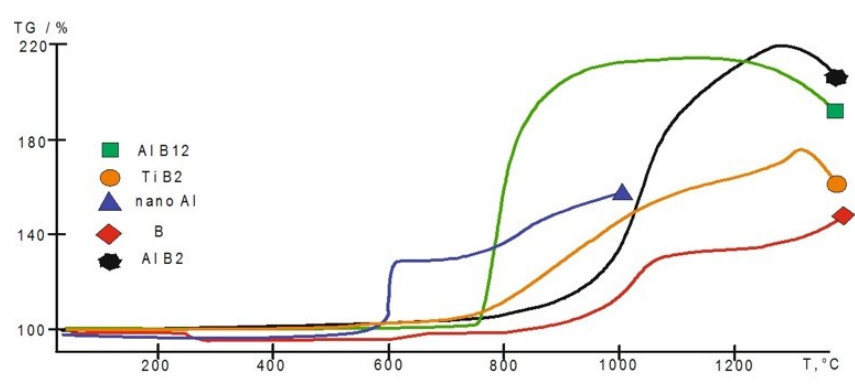

Fig. 6. TG general information (mass variation and corresponding temperatures) on all received oxidation borides compared with aluminum and boron.

The obtained data can be explained by the following mechanisms. Oxidation of aluminum occurs in several stages [16]. In the first stage (up to $500{ }^{\circ} \mathrm{C}$ ), the oxidation rate of aluminum is controlled by a thin (2 - $4 \mathrm{~nm}$ ) amorphous oxide layer that limits the diffusion of oxygen to the particle. At $600{ }^{\circ} \mathrm{C}$ the continuity of the oxide layer is disturbed, which leads to a sharp increase in the rate of oxidation, when the continuity is restored, the oxidation rate decreases and changes periodically, which is due to a number of polymorphous transformations. When the temperature reaches $1000{ }^{\circ} \mathrm{C}$, the degree of oxidation of aluminum is less than $70 \%$. Considering the data [17], it can be assumed that when the temperature reaches $1500{ }^{\circ} \mathrm{C}$, the degree of oxidation of aluminum is over $90 \%$. Oxidation of boron, most likely, proceeds by the same mechanism as the oxidation of aluminum. But due to the melting of boron oxide at $450{ }^{\circ} \mathrm{C}$, which is a viscous liquid, oxygen diffusion slows down. Because of this, even when relatively low temperatures are reached, the rate of oxidation of boron decreases, and amounts to small values, which results in the boron being not fully oxidized at $1400{ }^{\circ} \mathrm{C}$ the degree of boron oxidation reaches only $20 \%$ [18-20]. In the oxidation of aluminum borides, the resulting oxides of boron and aluminum at a temperature below $1035{ }^{\circ} \mathrm{C}$ form an oxide by the reaction:

$$
2 \mathrm{Al}_{2} \mathrm{O}_{3}+\mathrm{B}_{2} \mathrm{O}_{3}=\mathrm{Al}_{4} \mathrm{~B}_{2} \mathrm{O}_{9}
$$

which if it reaches a temperature of $1035{ }^{\circ} \mathrm{C}$ and higher, turns into $\mathrm{Al}_{18} \mathrm{~B}_{4} \mathrm{O}_{33}$ oxide $[21,22]$. Since boron oxide melts at $450{ }^{\circ} \mathrm{C}$, the oxides of aluminum and boron contact and therefore react to form borates, which in turn remove liquid $\mathrm{B}_{2} \mathrm{O}_{3}$ from the surface of the particles. For this reason, borides oxidize more intensively than boron, with higher speed and greater completeness.

\section{Conclusions}

The principle possibility of producing aluminum and titanium borides with a predetermined morphology is demonstrated using the SHS method and plasma processing. It was found that the synthesized metal borides, according to the thermal analysis data, are promising as a fuel in high-energy materials: the oxidation state of $\mathrm{AlB}_{2}$ is $\sim 80 \%$, at a degree of boron oxidation $\sim 20 \%$, aluminum $\sim 67 \%$.

Studies related to plasma processing of powders was funded by RFBR, according to the research project No. 16-38-60031 mol_a_dk.

\section{References}

1. A. Gany, Int. J. Energ. Mater. Chem. Propul., 2, 91112 (1993)

2. K. L. Chintersingh et al., Comb. and Flame, 172, 194-205 (2016)

3. A.B. Vorozhtsov et al., Sci. Tech. Energetic Materials, 76, 105-109 (2015)

4. Y. Wang, T. Xu, L. Liu, Sci. Tech. Energetic Materials, 75, 21-27 (2014) 
5. W. Ao et al., Propellants, Explosives, Pyrotechnics, 39, 185-191 (2014)

6. A. A. Gromov, and U. Teipel, eds. Metal nanopowders: production, characterization, and energetic applications. John Wiley \& Sons, 2014.

7. R. Kayikci, O. Kurtulus, R. Gurbuz, Solid State Phenomena, 144, 140-144 (2009)

8. I. Zlotnikov, I. Gotman, E.Y. Gutmanas, J. Europ. Ceram. Soc., 25, 3517-3522 (2005)

9. D.R. Lide (ed.): CRC Handbook of chemistry and physics (CRC Press, Boca Raton, 2005)

10. A. V. Grosse, J. B. Conway, Industrial \& Engineering Chemistry, 50 (4), 663-672 (1958)

11. I.A. Zhukov et al., Russian Physics Journal, 59, 1324-1326 (2016)

12. I. Zhukov, S. Bondarchuk and B. Borisov, MATEC Web of Conferences, 72, 1016 (2016)

13. I.S. Bondarchuk, I.A. Zhukov and B.V. Borisov, MATEC Web of Conferences, 23, p. 01046 (2015)

14. A.G. Merzhanov Solid Flame Combustion (Publishing House of Institute of Macrokinetics and Materials Sciences RAS, Chernogolovka, 2000)

15. I. A. Zhukov et al. Russian Physics Journal, 59, 1324-1326 (2016)

16. M.A. Trunov, M. Schoenitz and E.L. Dreizin, Combustion Theory and Modelling, 10, 603-623 (2006)

17. M.A. Trunov et al. Combustion and Flame, 140, 310-318 (2005)

18. B. Hussmann and M. Pfitzner, Combustion and Flame, 157, 803-821 (2010)

19. B. Hussmann and M. Pfitzner, Combustion and Flame, 157, 822-833 (2010)

20. C.L. Yeh and K.K. Kuo, Progress in Energy and Combustion Science, 22, pp. 511-541(1996)

21. T. Nagai, Y. Ogasawara and M. Maeda, The Journal of Chemical Thermodynamics, 41, 1292-1296 (2009)

22. K. Grente, F. Rebillat and F. Langlais 203rd Meeting, Paris, France (2003) 